\title{
The role of fiberoptic sinoscopy in evaluation the effect of surgically rapid maxillary expansion on the nasal airways
}

\author{
Mahmoud M. El Bahrawy ${ }^{1 *}$, Mohammad A. Shuman ${ }^{2}$
}

Codex : 03/2021/04

Aadj@azhar.edu.eg

\section{KEYWORDS}

Surgical rapid maxillary expansion, orthognathic surgery, nasal air way, nasal passage, nasofibroscopy.

1. Department of Otorhinolaryngology ,Faculty of Medicine , Assiut, Al-Azhar University, Egypt.

2. Department of Oral and Maxillofacial Surgery, Faculty of Dental Medicine, Assiut, AlAzhar University, Egypt.

* Corresponding Author e-mail: mahmoudelbahrawy.el20@azhar.edu.eg

\begin{abstract}
Aim : To evaluate the effect of surgically assisted rapid maxillary expansion on the nasal airway assissted by nasofibroscopy. Subjects and methods: Nine Patients were included in the present study. They were consecutive patients selected from the oral and maxillofacial surgery department that referred from orthodontic department Faculty of Dental Medicine, Al-Azhar University, Assuit branch in the period from September 2017 to October 2019 . They were adult patients of both sexes ( 3 males and 6 females). All patients were subjected to history taking, sinoscopic nasal examination. All patients had maxillary transverse deficiency associated primarily with functional impairments, such as posterior uni- or bilateral cross bite, dental crowding, reduced nasal respiratory function or anterior-posterior skeletal anomalies and they were indicated for surgically assisted rapid maxillary expansion. Preoperative intracanine and intramolar distances (C1, C2, M1, M2 ) was measured by digital caliper on Study cast. Measuring area of both nasal cavities by nasofibroscopy were done in ENT department of Al Azhar university hospital, Assuit. The operation was conducted under general anesthesia. After surgery, clinical evaluations ware done at intervals of 2, 4, 7 and 15 days and then all data obtained from nasofibroscopy by pixels and transformed by typography program in to millimeters. Result: Results of the current study have indicated that nasofibroscopy showed that was improvement in nasal obstruction after maxillary expansion. Conclusion: Surgically assisted rapid maxillary expansion is an effective method of widening the nasal passages and reducing nasal resistance that assisted by nasofibroscopy.
\end{abstract}

\section{INTRODUCTION}

The maxilla is essential component of midface that has both functional and aesthetic roles. It contributes to facial appearance;supports critical function such as mastication, speech, deglutition and respiration. A correct transverse skeletal relationship between the jaws is essential for stable and functional occlusion. ${ }^{(1-3)}$ 
Maixllry tansverse deficiency (MTD) is characterized by a narrow maxilla in relation to the rest of the craniofacial structures, a narrow palatal vault, and often a posterior cross bite. ${ }^{(4,5)}$ It is a pathological condition that may be associated with respiratory problems as narrow nasal cavity, which increases the resistance to nasal airway flow. ${ }^{(6-9)}$ The etiology of MTD is multifactorial, including congenital, genetic, developmental, traumatic or iatrogenic factors. Examples of causative factors are different syndromes, thumb and finger-sucking habits, mouth breathing during critical growth periods, trauma or iatrogenic injuries after cleft palate repair. ${ }^{(10,11)}$

Rapid maxillary expansion (RME) is one of the most frequent methods used by orthodontic to treat this problem. RME is based on the concept of widening the dental arch by means of opening the mid palatal suture. Rapid maxillary expansion has been used to increase nasal passage, correct posterior cross bite and increase arch perimeter to relieve crowding and tooth size-arch length discrepancies. Although conventional rapid maxillary expansion can be used in younger patients, the facial suture lines become significantly more interdigitated and become either partially or totally fused as individuals aged. ${ }^{(12,13)}$

RME uses orthopedic forces to separate the two halves of the maxilla at the mid-palatal suture. This is accomplished with an expansion screw that is anchored to the maxillary teeth and is typically activated 0.5 to $1 \mathrm{~mm}$ per day. ${ }^{(14-16)}$

Surgically assissted rapid maxillary expansion (SARME) as recommended by Bell and Epker are a well-established method for correction of transverse maxillary deficits in nongrowing patients. Crossbite and crowded teeth are a typical characteristic of maxillary compression syndromes. ${ }^{(17)} \mathrm{RME}$ and SARME can affect both skeletal and dental shape and the size of the nasal passages and airway resistance, favoring improved nasal respiration. ${ }^{(18)}$

Acoustic rhinometry, computed rhinomanometry and nasofibroscopy are the most specific and objective methods currently used to assess nasal patency, while CT and MRI are too costly for use. Nasofibroscopy has revolutionized the diagnostic method nowadays for oropharyngeal , nasopharyngeal regions and is able to show a large variety of etiologic factors that cause the obstruction of the upper airway. ${ }^{(19-20)}$

The present study was evaluate the effect of surgical assisted rapid maxillary expansion on nasal airways.

\section{SUBJECTS AND METHODS}

\section{1- Study sitting:}

The present study was approved by the medical Research Ethics Committee at Al-Azhar (Assiut branch) University and was carried out following the code of Ethics of the 1964 Declaration of Helsinki and its 2013 revision. Informed consent was obtained from all patients.

\section{2- Study design and patient selection:}

Nine Patients were included in the present study. They were consecutive patients selected from the oral and maxillofacial surgery department that referred from orthodontic department Faculty of Dental Medicine, Al-Azhar University, Assuit branch in the period from September 2017 to October 2019. They were adult patients of both sexes ( 3 males and 6 females). All patients had maxillary transverse deficiency associated primarily with functional impairments, such as posterior uni- or bilateral cross bite, dental crowding, reduced nasal respiratory function or anterior-posterior skeletal anomalies and they were indicated for surgically assisted rapid maxillary expansion.

\section{Criteria of case selection:}

\section{Inclusion criteria:}

Patients were in a good general health, above 14y old, had transverse maxillary deficiency, sufficient healthy soft tissue and all with good oral hygiene measures. 


\section{Exclusion criteria:}

Patient with any systemic condition that might complicate the surgical procedure.

Psychological problem, Individuals presenting with clefts or craniofacial syndromes, heavy smokers, and bad oral hygiene.

\section{3- study procedure:}

All patients were subjected to history taking, then all patients underwent clinical examination by inspection and palpation of soft tissue for detection of any soft tissue lesion or any bony abnormalities. Impression was taken and study model then mounted on articulator ( Fig.1-A,B).

\section{Preparation and measurements:}

Intracanine and intramolar distances was measured by digital caliper. Direct measurements on study models were made with a digital sliding caliper. Measurements were taken at two reference points on the canine's and the first molars respectively, according to Moorrees ${ }^{(23)}$, to measure intramaxillary distance anteriorly and posteriorly. CI denotes the distance between the canines tip and CII the distance between the most prominent point of the canine's cingulum. MI represents the distance measured between the mesobuccal cusps tips of the maxillary first molars and MII the distance between the most cervical points of the palatal fissure of the maxillary first molars.

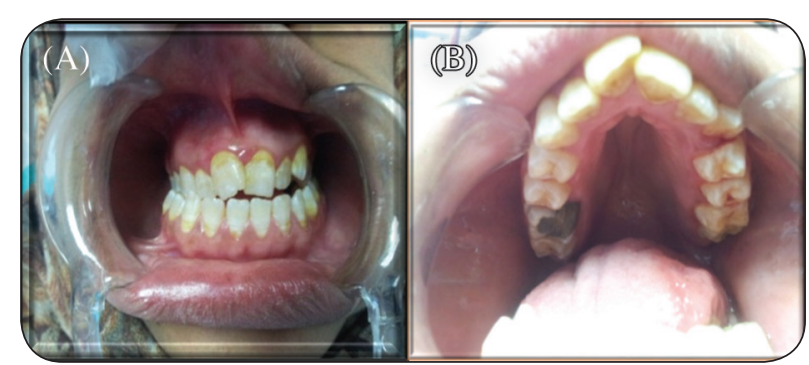

Fig. (1-a,b):A photographs showing of patient with cross biteand patient with transverse maxillary deficiency respectively.

\section{Nasofibroscopy examination:}

Nasofibroscopy measurements was performed by nasofibroscopy equipment. (24) It was done in ENT department of Al-Azhar University Hospital, Assuit by nasofibroscopy: A Xenon Nova 20131520 Karl Storz, Endoscope light source, a micro camera Watec WAT-202B Color Camera, 0-degree wideangled telescopes, and CM $1300 \mathrm{~K}$ television .Nasofibroscopy; measuring of both nasal cavities. (Fig.2-A,B).

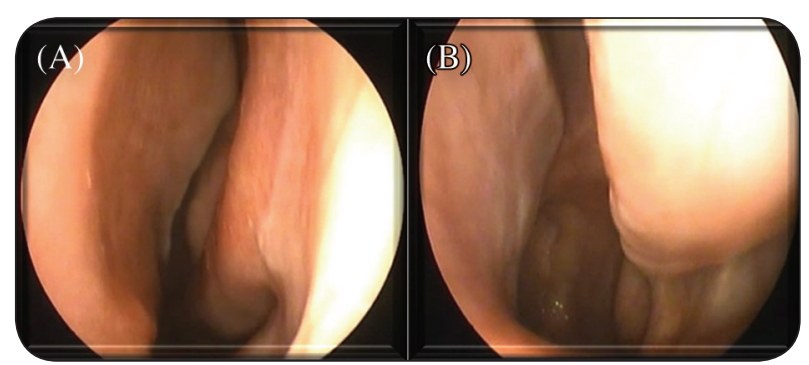

Fig. (2-A,B): A photographs showing nasofibroscopy for ANC. and for PNC respectively.

\section{A Hyrax device installation:}

The selected device was tooth-borne hyrax appliance consists of a soldered framework and activated by means of a conventional Hyrax expander using a jackscrew in the midline. Toothborn device with bands on the first bicuspids and first molars.After adjustment on study cast and preparation of patient hyrax expansion appliance was applied before surgery and was inactivated. Care should be taken to keep the screw-device well clear of the palate, so that there is no interference during the expansion phase (Fig3) .

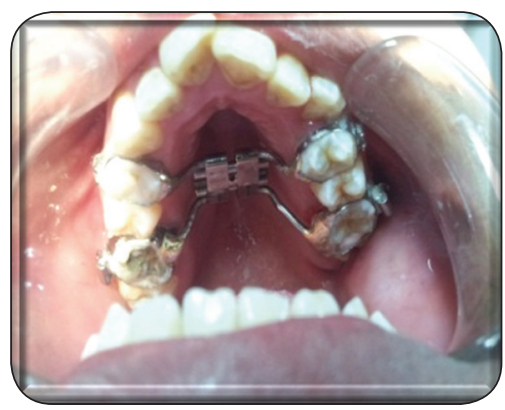

Fig. (3): A photographs showing installation and cementation of a hyrax expansion appliance. 


\section{Surrgical Technique of SARME}

In the operating room, Patients were prepared in general routine manner for operation under general anesthesia. Nasoendotracheal intubation was used in all cases, scrupulous disinfection of oral cavity and extraoral.

\section{Incision and flap elevation:}

After submucosal injection of vasoconstrictor intra oral incision was be made in the depth of the maxillary vestibule, $3-5 \mathrm{~mm}$ above the level of attached gingiva in the alveolar mucosa and leaving unattached mucosa on the alveolus to facilitate closure extended from second premolar on one side to second premolar in other side. The soft tissues are reflected subperiosteally by periosteal elevator from the lateral aspect of the maxilla, with dissection to expose the anterior floor of the nose and piriform aperture area, posteriorly toward the pterygomaxillary fissure.

\section{Osteotomies and Hyrax device activation;}

Osteotomy by using of surgical bur and the level of the lateral maxillary osteotomies is done to be at least $5 \mathrm{~mm}$ above the apices of the teeth. As the anterior portion of the osteotomies is being performed, periosteal elevator is maintained in the piriform rim, lifting the nasal mucoperiosteum to protect it. The lateral wall osteotomies are extended posteriorly toward the pterygo-maxillary fissure (Fig. 4-A).

On completion of the lateral maxillary osteotomy, a periosteal elevator is passed subperiosteally, posteriorly into the lateral wall of the nose. This is used to protect the nasal mucoperiosteum while osteotome is malleted posteriorly for approximately $30 \mathrm{~mm}$, to section the lateral nasal wall. Similar osteotomies are performed on the opposite side. The nasal spine and septum are now released with osteotome extending at least $30 \mathrm{~mm}$ posteriorly, having first performed an osteotomy below the nasal spine, leaving it attached to the septum and ensuring that the septum remains independent of the maxillary segments.

A midpalatal osteotomy is then accomplished by malletting an osteotome posteriorly, parallel to the palatal plane, into the intermaxillary suture and directed to the posterior nasal spine. These procedures ensure that separation of the entire midpalatal suture has occurred, the expansion screw is turned eight to twelve times, so that the maxilla is expanded 2 to $3 \mathrm{~mm}$ this amount of immediate expansion would normally cause blanching of the incisal gingival tissues. Before the soft tissue incisions are closed the hyrax deactivated by the same amount.

Closure: Finally, the wounds were closed as for a total maxillary osteotomy, taking care to reapproximate the musculature with deep periosteal sutures. Flap was returned to original position then pressed on the flap for a minute before suturing to gain initial adherence then sutured with 3-0 black silk suture by interrupted suturing technique. (Fig.4-B).

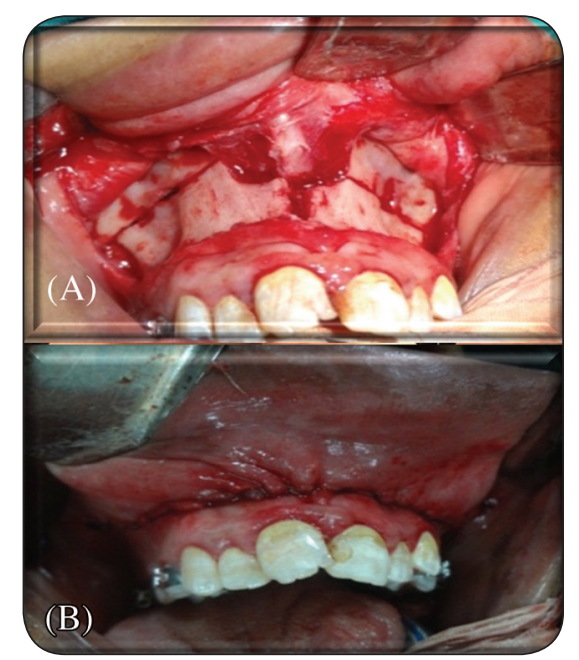

Fig. (4-A,B ):A photographs showing of bilateral osteotomy and closure of operation site by interrupted suture.

\section{Expansion protocol:}

Following the SARME procedure and after seven days' latency period and oral analgesic before expansion for controlling of pain the appliance is activated by the parents of patient, one millimeter 
each day, until the desired expansion has been achieved. It was expanded to its maximum width, because it is easier to allow the maxillary posterior segments to settle back, if necessary, into ideal transverse relationships with their lower opponents.

\section{Follow up \&Post-operative Evaluation:}

\section{I- Clinical evaluation :}

Clinical evaluations were done at intervals of 2, 4, 7 and 15 days and directed toward the observation of the healing process, infection or any complications of wound healing. (Fig.5-A,B,C,D).

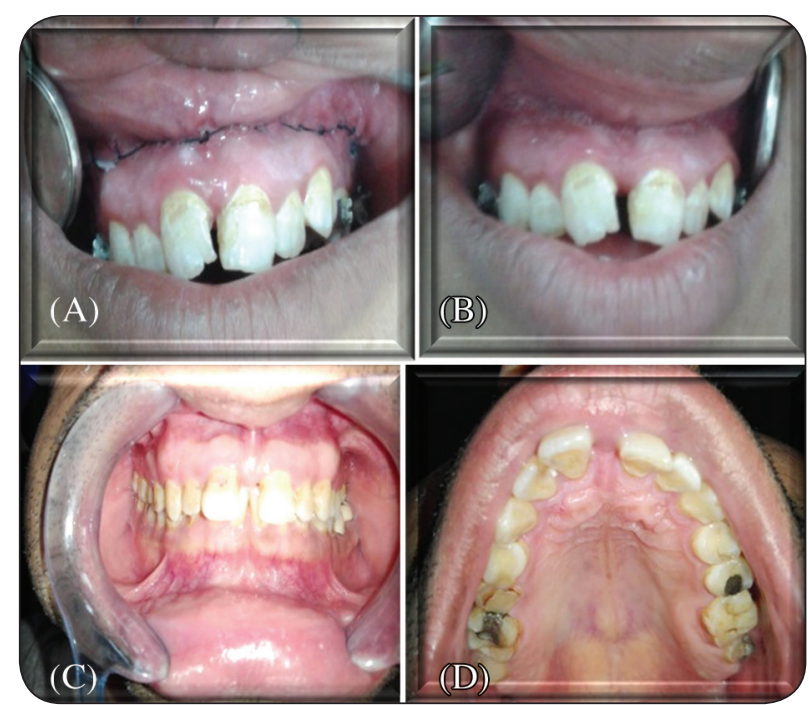

Fig. (5-A,B,C,D): A photographs showing of operation site at 2 days, 7 days , 15 days and after complete expansion.

\section{Study model:}

Intracanine and intramolar distances will be measured by digital caliper after treatment was completed .

\section{Nasofibroscopy;}

Nasofibroscopy; was performed postoperatively at 3-6 months after expansion T3, T4, T5, and T6 in ENT department, of Al-Azhar University hospital, Assiut branch. All measurements were done in the seated posture. Nasal image was captured with resolution of $75 \times 75$ pixels.

\section{Data Processing:}

All data were processed so that any point in nasal cavity is located by the (X, Y, and Z) coordinates as introduced in. figure (6). After correction of the $\mathrm{X}$, and $\mathrm{Y}$, cross section of the fiberoscope and focusing of the region of interest (ROI) using a cross-correlation technique, initially on the first image the ROI was chosen and traced by hand. After surgery, in the postoperative image, the crosscorrelation coefficient of the precedent ROI is calculated at all possible positions and transferred to the actual image. The coordinates with highest cross-correlation coefficient value are then chosen for new ROI.

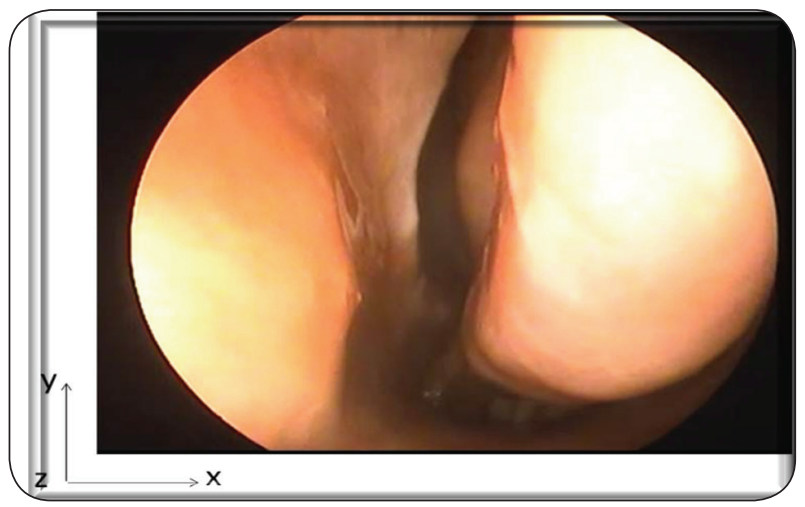

Fig. (6) Showing nasofibroscopy with (X, Y, and Z) coordinates.

A- Detection of the nasal cavities contours applying a geometric active contours function to identify object boundaries. This model requires choosing a proposed by Scheinherr et al. ${ }^{(25)}$ This algorithm is an edge-based active contour method, using the image gradients initial contour before expansion. Therefore, the nasal cavity was drawn by hand on the images yellow curve representing the initial contour before expansion and the red curves representing the active contours function after palatal expansion.

B- Determination of nasal cavity antero-posterior diameter (APg). At first a contouring of nasal cavity and two points were detected on the most right and left nasal cavity contour. From 
intersecting of those border lines, central line was derived, at last, the distance (APg) was defined by the cross points of the central lines with nasal cavity contour ${ }^{(25)}$.

C- Determination of nasal cavity width (dg). This distance was determined by perpendicular line to APg at it is mid-level. ${ }^{(25)}$ Finally, conversion of the measured data from pixels to millimeters by typography converter program .

\section{Statistical analysis}

Numerical data were presented and analyzed using software program SPSS statistical packaged for social sciences V19.0 for windows (SPSS INC, Chicago, USA), the significant level was set at $\mathrm{p} \leq .0 .05$.

\section{RESULTS}

\section{Clinical findings:}

In the present study, all patients treated by surgical assisted rapid maxillary expansion. Two patients were excluded from the study due to complete relapse due to screw loosing. Intracanine and intramolar distances were measured by digital caliper. A hyrex device was installed and cemented before surgery.

All patients were observed clinically for two weeks after surgery on 2, 4, 7, and 15 days. Postoperative edema was evident after 24 hours that had been subsided within 4 to 5 days after operation. After 15 days the area of operation almost appeared normal.

In the present study, signs of infection, evidence of pain, and evidence of looseness of teeth that related to operation site were not detected along the observation periods. In all patients, the distractor device was well tolerated, remained stable, maintained the osteotomized segments during distraction in the desired alignment. Distraction was carried out manually and continued for 10 days without any difficulty.

\section{Statistical analysis of Study model findings:}

At completed treatment: The expansion was statistically significant (Table 2). Depending on the clinical need for expansion, there was a major inter individual variance in the degree of expansion. The greatest expansion was recorded for MI the distance between the tips of the buccal cusps of the maxillary first molars .

Table (1) Comparison between maxillary intracanine and intramolar distances for the treated subjects at baseline and after completed treatment.

\begin{tabular}{|c|c|c|c|c|}
\hline & Mean (mm)s & $\mathrm{SD}(\mathrm{mm})$ & t- value & $\mathrm{P}$ value \\
\hline \multirow{2}{*}{$\mathrm{C} 1(\mathrm{~B})-\mathrm{C} 1(\mathrm{~A})$} & 31.01429 & 0.693851 & \multirow{2}{*}{-26.834} & \multirow{2}{*}{0.000} \\
\hline & 34.75714 & 0.450397 & & \\
\hline \multirow{2}{*}{$(\mathrm{C} 2(\mathrm{~B})-\mathrm{C} 2(\mathrm{~A})$} & 23.72857 & 0.468025 & \multirow{2}{*}{-6.912} & \multirow{2}{*}{0.000} \\
\hline & 26.58571 & 1.487087 & & \\
\hline \multirow{2}{*}{ M1(B)-M1(A)) } & 40.21429 & 1.185227 & \multirow{2}{*}{-81.376} & \multirow{2}{*}{0.000} \\
\hline & 46.84286 & 0.962388 & & \\
\hline \multirow{2}{*}{ M2(B) -M2(A) } & 25.81429 & 0.654290 & \multirow{2}{*}{-39.025} & \multirow{2}{*}{0.000} \\
\hline & 31.71429 & 0.628301 & & \\
\hline
\end{tabular}

Significant at $P \leq 0.05 . \quad B$ (Before expansion) $\quad$ A(After expansion) 
III. Statistical analysis of nasofibroscopy findings:

Table 2 ( A ,B ): Mean Width changes (dg) of the right side for ANC and PNC respectivly.

\begin{tabular}{c|c|c|c|c}
\hline A & Mean & Std.Dv & t-Value & P \\
\hline \multirow{2}{*}{ T0 - T3 } & 3.414 & 0.555 & \multirow{2}{*}{-13.779} & \multirow{2}{*}{$0.000^{*}$} \\
\cline { 2 - 3 } & 4.117 & 0.469 & & \\
\hline \multirow{2}{*}{ T0 - T4 } & 3.414 & 0.555 & \multirow{2}{*}{-16.282} & \multirow{2}{*}{$0.000^{*}$} \\
\cline { 2 - 4 } & 4.066 & 0.491 & & \\
\hline \multirow{2}{*}{ T0 - T5 } & 3.414 & 0.555 & \multirow{2}{*}{-9.400} & $0.000^{*}$ \\
\cline { 2 - 3 } & 3.936 & 0.380 & & \\
\hline \multirow{2}{*}{ T0 - T6 } & 3.414 & 0.555 & \multirow{2}{*}{-9.400} & $0.000^{*}$ \\
\cline { 2 - 3 } & 3.936 & 0.380 & & \\
\hline
\end{tabular}

\begin{tabular}{c|c|c|c|c}
\hline B & Mean & Std.Dv & t-Value & $\mathrm{P}$ \\
\hline \multirow{2}{*}{ T0 - T3 } & 3.729 & 0.373 & \multirow{2}{*}{-13.856} & \multirow{2}{*}{$0.000^{*}$} \\
\cline { 2 - 4 } & 4.529 & 0.364 & & \\
\hline \multirow{2}{*}{ T0 - T4 } & 3.729 & 0.373 & \multirow{2}{*}{-4.515} & \multirow{2}{*}{$0.000^{*}$} \\
\cline { 2 - 4 } & 4.478 & 0.282 & & \\
\hline \multirow{2}{*}{ T0 - T5 } & 3.729 & 0.373 & \multirow{2}{*}{-13.664} & $0.000^{*}$ \\
\cline { 2 - 4 } & 4.386 & 0.302 & & \\
\hline \multirow{2}{*}{ T0 - T6 } & 3.729 & 0.373 & \multirow{2}{*}{-13.664} & $0.000^{*}$ \\
\cline { 2 - 3 } & 4.386 & 0.302 & & \\
\hline
\end{tabular}

* Significant at $P \leq 0.05$ for both a $t A$ and $B$.

Table 3 ( A,B ): Mean Width changes ( $d g$ ) of the left side for ANC and PNC respectively.

\begin{tabular}{c|c|c|c|c}
\hline $\mathbf{A}$ & Mean & Std.Dv & t-Value & $\mathrm{P}$ \\
\hline \multirow{2}{*}{$\mathrm{T} 0$ - T3 } & 3.486 & 0.546 & \multirow{2}{*}{-16.016} & \multirow{2}{*}{$0.000^{*}$} \\
\cline { 2 - 4 } & 4.200 & 0.447 & & \\
\hline \multirow{2}{*}{$\mathrm{T} 0$ - T4 } & 3.486 & 0.546 & \multirow{2}{*}{-18.343} & \multirow{2}{*}{$0.000^{*}$} \\
\cline { 2 - 4 } & 4.137 & 0.454 & & \multirow{2}{*}{$0.000^{*}$} \\
\hline \multirow{2}{*}{$\mathrm{T} 0$ - T5 } & 3.486 & 0.546 & \multirow{2}{*}{-11.500} & \\
\cline { 2 - 4 } & 4.023 & 0.431 & & \multirow{2}{*}{$0.000^{*}$} \\
\hline \multirow{2}{*}{$\mathrm{T} 0-\mathrm{T} 6$} & 3.486 & 0.546 & \multirow{2}{*}{0.500} & \\
\cline { 2 - 3 } & 4.023 & 0.431 & & \\
\hline
\end{tabular}

\begin{tabular}{c|c|c|c|c}
\hline B & Mean & Std.Dv & t-Value & P \\
\hline \multirow{2}{*}{ T0 - T3 } & 3.786 & 0.302 & \multirow{2}{*}{-20.000} & \multirow{2}{*}{$0.000^{*}$} \\
\cline { 2 - 4 } & 4.643 & 0.346 & & \\
\hline \multirow{2}{*}{ T0 - T4 } & 3.786 & 0.302 & \multirow{2}{*}{-6.407} & \multirow{2}{*}{$0.000^{*}$} \\
\cline { 2 - 3 } & 4.592 & 0.550 & & \multirow{2}{*}{$0.000^{*}$} \\
\hline \multirow{2}{*}{ T0 - T5 } & 3.786 & 0.302 & \multirow{2}{*}{-5.891} & \\
\cline { 2 - 3 } & 4.541 & 0.549 & & \multirow{2}{*}{$0.000^{*}$} \\
\hline \multirow{2}{*}{ T0 - T6 } & 3.786 & 0.302 & \multirow{2}{*}{-5.891} & \\
\cline { 2 - 3 } & 4.536 & 0.549 & & \multicolumn{2}{|c}{} \\
\hline
\end{tabular}

*Significant at $P \leq 0.0$ bothA and $B$.

Table 4 (A, B): Mean Anteroposterior diameter changes (Apg) of the right side for ANC and PNC respectively.

\begin{tabular}{c|c|c|c|c}
\hline A & Mean & Std.Dv & t-Value & P \\
\hline \multirow{2}{*}{ T0 - T3 } & 3.929 & 0.390 & \multirow{2}{*}{-20.622} & \multirow{2}{*}{$0.000^{*}$} \\
\cline { 2 - 3 } & 4.429 & 0.479 & & \\
\hline \multirow{2}{*}{ T0 - T4 } & 3.929 & 0.390 & \multirow{2}{*}{-20.000} & \multirow{2}{*}{$0.000^{*}$} \\
\cline { 2 - 4 } & 4.586 & 0.426 & & \\
\hline \multirow{2}{*}{ T0 - T5 } & 3.929 & 0.390 & \multirow{2}{*}{-8.402} & \multirow{2}{*}{$0.000^{*}$} \\
\cline { 2 - 3 } & 4.457 & 0.555 & & \\
\hline \multirow{2}{*}{ T0 - T6 } & 3.929 & 0.390 & \multirow{2}{*}{-9.285} & $0.000^{*}$ \\
\cline { 2 - 3 } & 4.443 & 0.489 & & \\
\hline
\end{tabular}

\begin{tabular}{c|c|c|c|c}
\hline B & Mean & Std.Dv & t-Value & $\mathrm{P}$ \\
\hline \multirow{2}{*}{ T0 - T3 } & 4.471 & 0.482 & \multirow{2}{*}{-20.721} & \multirow{2}{*}{$0.000^{*}$} \\
\cline { 2 - 3 } & 5.343 & 0.513 & & \\
\hline \multirow{2}{*}{ T0 - T4 } & 4.471 & 0.482 & \multirow{2}{*}{-10.331} & \multirow{2}{*}{$0.000^{*}$} \\
\cline { 2 - 3 } & 5.214 & 0.474 & & \\
\hline \multirow{2}{*}{ T0 - T5 } & 4.471 & 0.482 & \multirow{2}{*}{-13.664} & $0.000^{*}$ \\
\cline { 2 - 3 } & 5.129 & 0.461 & & \\
\hline \multirow{2}{*}{ T0 - T6 } & 4.471 & 0.482 & \multirow{2}{*}{-13.377} & $0.000^{*}$ \\
\cline { 2 - 3 } & 5.086 & 0.471 & & \\
\hline
\end{tabular}

*Significant at $P \leq 0.05$ for both $A$ and $B$. 
Table 5 (A, B ): Mean Anteroposterior diameter changes(Apg) of the left side for ANC and PNC respectively.

\begin{tabular}{|c|c|c|c|c|c|c|c|c|c|}
\hline $\mathbf{A}$ & Mean & Std.Dv & t-Value & $\mathrm{P}$ & B & Mean & Std.Dv & t-Value & $\mathrm{P}$ \\
\hline \multirow{2}{*}{$\mathrm{T} 0$ - T3 } & 3.957 & 0.416 & \multirow{2}{*}{-41.719} & \multirow{2}{*}{$0.000^{*}$} & \multirow{2}{*}{$\mathrm{T} 0$ - T3 } & 4.457 & 0.424 & \multirow{2}{*}{-19.445} & \multirow{2}{*}{$0.000^{*}$} \\
\hline & 4.650 & 0.416 & & & & 5.243 & 0.416 & & \\
\hline \multirow{2}{*}{$\mathrm{T} 0-\mathrm{T} 4$} & 3.957 & 0.416 & \multirow{2}{*}{-18.343} & \multirow{2}{*}{$0.000 *$} & \multirow{2}{*}{$\mathrm{T} 0$ - T4 } & 4.457 & 0.424 & \multirow{2}{*}{-15.743} & \multirow{2}{*}{0.000 * } \\
\hline & 4.579 & 0.457 & & & & 5.214 & 0.426 & & \\
\hline \multirow{2}{*}{$\mathrm{T} 0$ - T5 } & 3.957 & 0.416 & \multirow{2}{*}{-17.428} & \multirow{2}{*}{$0.000^{*}$} & \multirow{2}{*}{ T0 - T5 } & 4.457 & 0.424 & \multirow{2}{*}{-12.296} & \multirow{2}{*}{$0.000 *$} \\
\hline & 4.480 & 0.392 & & & & 5.057 & 0.489 & & \\
\hline \multirow{2}{*}{ T0 - T6 } & 3.957 & 0.416 & \multirow{2}{*}{-10.586} & \multirow{2}{*}{$0.000^{*}$} & \multirow{2}{*}{ T0 - T6 } & 4.457 & 0.424 & \multirow{2}{*}{-12.060} & \multirow{2}{*}{0.000 * } \\
\hline & 4.443 & 0.393 & & & & 5.029 & 0.486 & & \\
\hline
\end{tabular}

* Significant at $P \leq 0.05$ for both $A$ and $B$.

\section{DISCUSSION}

In this study all patients were selected from adult patients above 14 years with skeletal maturity. Surgically assisted rapid maxillary expansion has showed good results, therefore, it has been considered a safe, stable, and efficient procedure for treating transversal deficiency of maxilla.

In this study we found that SARME also associated with structures of nasal cavity. This could generate, for example, the increase of both the nasal volume and the internal nasal spaces, which has occurred by the lateral movement of the lateral walls of the nasal cavity, due to the maxillae separation, being this increase higher in the base region of the nasal cavity 'The patient acceptance of the SARME procedure is high as the surgery is little compared to LeFort I and give similar stabilities of transverse expansion of the dental arches. When only a transverse change is needed, SARME would be the treatment of choice. ${ }^{(21,22)}$

In the Present study we measured area changes in nasal cavities after surgical assisted rapid maxillary expansion by nasofibroscopy and including antero-posterior diameter (APg) and nasal cavity width (dg) for right (anterior and posterior) and left (anterior and posterior) nasal cavities, T0, and T3, T4 T5, and T6 after expansion postoperatively to follow up. In this study, increases in area were observed in ANC, and PNC at T0-T3, T0-T4, T0-T5 and T0-T6. And these results would have supported by the studies that demonstrated a reduction in NAR after expansion. ${ }^{(26-28)}$

According to the results of the study, it could be stated that surgically assisted rapid maxillary expansion in adult patients was simple and effective procedure for the treatment of transverse maxillary deficiency an effective method of widening the nasal passages. Nasofibroscopy has a good role in evaluation of nasal airways.

\section{CONCLUSIONS}

Based upon the findings of the present study it could be concluded that:

1. Surgically assisted rapid maxillary expansion is an effective method of widening the nasal passages and reducing nasal resistance.

2. The nasofibroscopy has the ability to measure the area changes of nasal cavities. 


\section{REFERENCES}

1. Subramania I, and Krishnakumar T. Maxillary reconstruction: Current concepts and controversies. Indian J Plast Surg. $2014 ; 47: 8-10$.

2. Robert L, and Vanarsdall Jr. Transverse dimension and long-term stability. Semin Orthod 1999; 5:171-80.

3. Wertz R A, Kankakee US. Skeletal and dental changes accompanying rapid midpalatal suture opening. Am J Orthod 1970; 58: 41-66.

4. Thomas M. and Doris G E. Maxillary transverse deficiency. American Journal of Orthodontics and Dentofacial Orthopedics, 2000; 1:540-4.

5. Zemann W, Schanbacher M, Feichtinger M, Linecker A, Kärcher H. Dentoalveolar changes after surgically assisted maxillary expansion: a three-dimensional evaluation, Oral Surg Oral Med Oral Pathol Oral Radiol Endod, 2009; 107: $36-42$.

6. Ana Célia F, Samuel P. Enlargement of the Pharynx Resulting from Surgically Assisted Rapid Maxillary Expansion. Int J Oral Maxillofac Surg 2016; 74:369-79.

7. Landes CA, Laudemann K, Petruchin O, Ludwig B. Comparison of bipartite versus tripartite osteotomy for maxillary transversal expansion using 3-dimensional preoperative and post expansion computed tomography data. J Oral Maxillofac Surg 2009; 67: 2287-301.

8. Lobato HI, Machado SM, Ribeiro SM. Airway flow and audiologic ability evaluation after rapid maxillary expansion case report. Int J Pediatric Otorhinolaryngology Extra 2010; 5:89-90.

9. Chiari S, Romsdorfer P, Swoboda H, Ban-tleon H. Effects of rapid maxillary expansion on the airways and ears apilot study. Eur J Orthod 2009; 31: 135-41.

10. Larsson C, Millqvist E, Bende M. Relationship between subjective nasal stuffiness and nasal patency measured by acoustic rhinometry. Am J Rhinol 2001; 15: 403-5.

11. Ogaard B, Larsson E, and Lindsten R. The effect of sucking habits, cohort, sex, intercanine arch widths, and breast or bottle feeding on posterior crossbite in Norwegian and Swedish 3-year-oldchildren. Am J Orthod Dentofacial Orthop 1994; 106: 161-66.

12. Ioannidou J, Kolokitha O. Rapid maxillary expansion: presentation of 3 clinical cases. Orthod 2000; 71:95-103

13. Wehrbein H, Göllner P. Skeletal anchorage in orthodontics-basics and clinical application. J Orofac Orthop 2007; 68:443-61.
14. Kumar SA, Gurunathan D, Muruganandham SS. Rapid Maxillary Expansion: A Unique Treatment Modality in Dentistry. Journal of Clinical and Diagnostic Research 2011; 5:906-11.

15. Stevens K, Bressmann T G, Siew-Ging T, Bryan D. "Impact of a rapid palatal expander on speech articulation”. Am J Orthod Dentofacial Orthop. 2011; 140: 67-75.

16. Haas AJ, Andrew J, Cuyahoga F. Rapid expansion of the maxillary dental arch and nasal cavity by opening of the midpalatal suture. Angle Orthod 1961; 31:73-90.

17. Bell WH, Epker BN. Surgical orthodontic expansion of the maxilla. Am J Orthod 1976; 70: 517-28.

18. Basciftci FA, Mutlu N, Karaman AI, Malkoc S, Küçükkolbasi H. Does the timing and method of rapid maxillary expansion have an effect on the changes in nasal dimensions? Angle Orthod 2002; 72: 118-23.

19. Hilberg O. Objective measurement of nasal airway dimensions using acoustic rhinometry: methodological and clinical aspects Allergy 2002; 57: 5-39.

20. Edmilsson P J, Luiz G G. Evaluation of the effect of rapid maxillary expansion on the upper airway using nasofibroscopy: Case report and description of the technique. Dental Press J Orthod 2011; 16:81-9.

21. Gill D, Naini F, McNally M, Jones A. The management of transverse maxillary deficiency. Dent Update 2004; 31 : 516-23

22. Phillips C, Medland WH, Fields HW Jr, Proffit WR, White RP Jr. Stability of surgical maxillary expansion. Int J Adult Orthodon Orthognath Surg 1992; 7: 139-46.

23. Moorrees, C F A, The dentition of the growing child. (Cambridge): Harvard University Press 1959; 82: 910-12.

24. Edmilsson P J, Ary S, Luiz G J, Odilon G. Evaluation of the effect of rapid maxillary expansion on the upper airway using nasofibroscopy: Case report and description of the technique. Dental Press J Orthod 2011; 16:81-9

25. Scheinherr A, Darquenne C, Isabey D. Glottal motion and it is impact on airflow and aerosol deposition in upper airways during human breathing. Ann Otorhinolaryngol Suppl 2014;193: 15-18.

26. Cross DL, McDonald JP. Effect of rapid maxillary expansion on skeletal, dental, and nasal structures: a postero-anterior cephalometric study. Eur J Orthod 2000; 22:519-28.

27. Doruk C, Sokucu O, Sezer H, Canbay EI. Evaluation of nasal airway resistance during rapid maxillary expansion using acoustic rhinometry . Eur J Orthod 2004; 26:397-401.

28. Hershey HG, Stewart BL, Warren DW. Changes in nasal airway resistance associated with rapid maxillary expansion. Am J Orthod 1976; 69:274-84. 


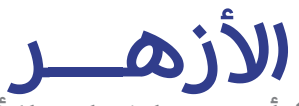 \\ مجلة أسيوط لطب الأسنان}

النشر الرسمي لكلية طب الأسنان جامعة الأزهر أسيوط الكانة

\title{
تأثير التمدد السريع للفك العلوم جراحيا علم مجرى التنفس الانفص
}

\author{
محمود محمد البحراوى1, * محمد عبد الحميلد شومان 2

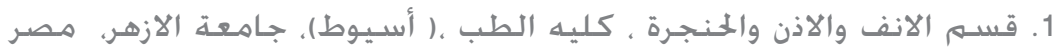

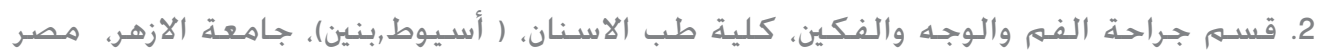 \\ :MAHMOUDELBAHRAWY.EL20@AZHAR.EDU.EG_البريد الإلكتروني للباحث الرئيسين * * *
}

الملخص :

الهـدف: أجريت هذه الدراسة لبحث تأثير التهدد السريع للفك العلوي جراحيا على مجرى التنفس الانفى.

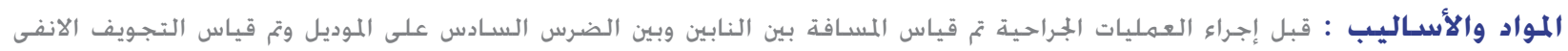

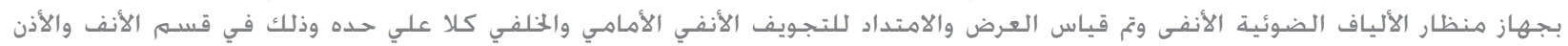

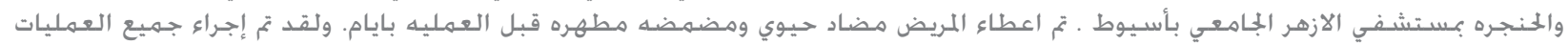

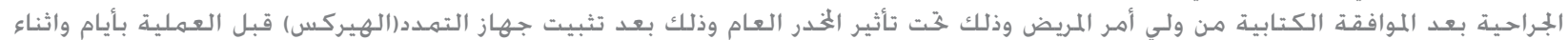

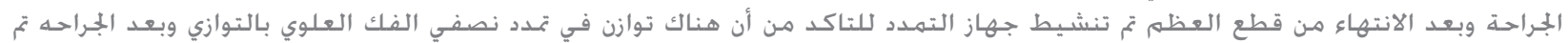

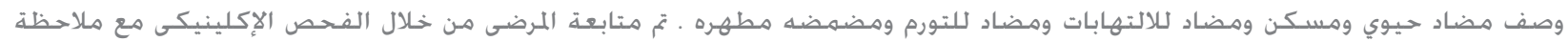

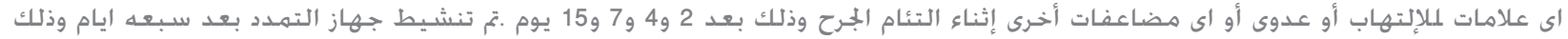

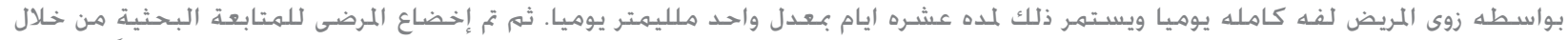

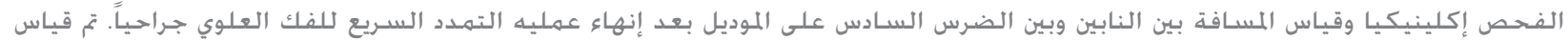

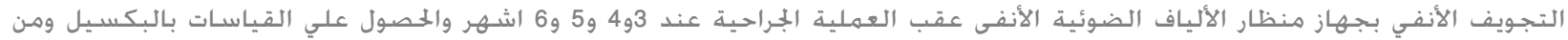
ثم ثُويلها ببرناهج التيبوجراف الي ملليمترات.

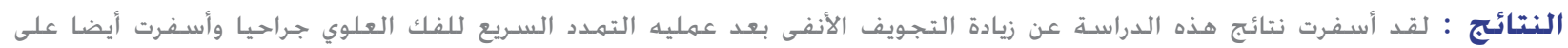
فاعلية استخدام جهاز منظار الألياف الضوئية الانفى في قياس التجويف الأنفى.

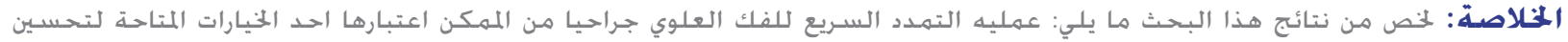

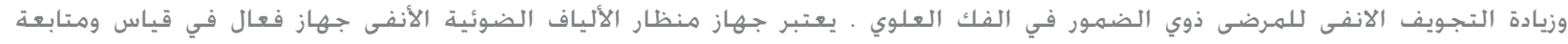
التجويف الأنفى للمرضى ذوى الضمور في النفك التهري العلوي.

الكلمات المفتاحية: التهدد السريع للفك العلوي جراحيا ، جراحه تقويميه, الممر الانفى , مجري التنفس الانفي ،و منظار الجيوب الانفية الدقيق. 